\title{
Might a beta blocker finally provide some relief from postoperative atrial fibrillation?
}

\author{
Spencer J. Melby, MD
}

\footnotetext{
From the Division of Cardiothoracic Surgery, Washington University in St Louis School of Medicine, and Barnes Jewish Hospital, St Louis, Mo.

Disclosures: Author has nothing to disclose with regard to commercial support.

Received for publication June 29, 2015; accepted for publication June 30, 2015; available ahead of print July 30, 2015.

Address for reprints: Spencer J. Melby, MD, Division of Cardiothoracic Surgery, Washington University in St Louis School of Medicine and Barnes Jewish Hospital, Box 8234, 660 S Euclid Ave, St Louis, MO 63110 (E-mail: melbys@ wustl.edu).

J Thorac Cardiovasc Surg 2015;150:965-6

$0022-5223 / \$ 36.00$

Copyright (c) 2015 by The American Association for Thoracic Surgery

http://dx.doi.org/10.1016/j.jtcvs.2015.06.084
}

Sezai and colleagues ${ }^{1}$ present a small study in which 60 patients with poor ventricular function were randomized after cardiac surgery to either an ultrashort-acting beta blocker (landiolol) or placebo. The results are promising: Only $10 \%$ of the treated group experienced postoperative atrial fibrillation, whereas $40 \%$ of the untreated group experienced the complication. Because postoperative atrial fibrillation is common, occurring in $30 \%$ to $40 \%$ of all patients undergoing cardiac surgery, and because the sequelae can be morbid (eg, increased risk of stroke, prolonged hospital stay, and a marker for decreased survival), this is an oftenignored but incredibly important complication that occurs frequently and remains without good prophylactic treatment. Many agents have been purported to decrease postoperative atrial fibrillation, and many trials have reported decreased rates with various interventions (including amiodarone, beta blockers, magnesium, atrial pacing, and other modalities), but these have been shown to be largely ineffective. Indeed, despite the recommendation from the American Heart Association and the American College of Cardiology that patients undergoing coronary artery bypass grafting be treated with a beta blocker, a large-scale retrospective review of patients who underwent coronary artery bypass grafting ( $>500,000$ patients) demonstrated that not only was there no decrease in rates of postoperative atrial fibrillation in patients who received beta blockers, but there was actually a slight increase. ${ }^{2,3}$ We have found at our institution that despite the widespread use of amiodarone and beta blockers in patients after cardiac surgery at Barnes Jewish Hospital, there has been no decrease in the actual rate of atrial fibrillation after cardiac surgery in the past 20 years. ${ }^{4}$ This common and morbid complication is crying out for better prophylaxis and treatment. Any effective medications that decrease the burden of this disease would be welcome.

Because this is a common morbidity after cardiac surgery and the most commonly used prophylactic treatments are ineffective, several factors make the results of the of the drug.

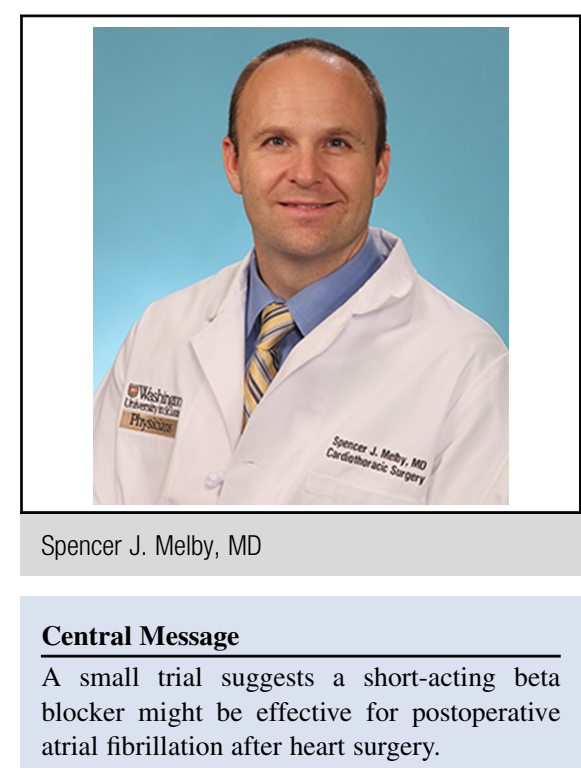

See Article page 957.

study by Sezai and colleagues ${ }^{1}$ intriguing. Perhaps beta blockade would be more helpful if patients could tolerate the doses required to decrease arrhythmias, but patients after cardiac surgery are notoriously labile in their blood pressure and often do not tolerate administration of any medication that slows heart rate or has negative inotropic effects during the immediate postoperative period. Landiolol has a very short half-life (4 minutes) and was not discontinued in any patient in this small trial for hypotension or bradycardia. This is an important point, because the more commonly used beta blockers are often not tolerated due to these side effects. Furthermore the high beta- 1 selectivity of landiolol results in greater effects on heart rate than on blood pressure. These characteristics make it a good choice for postoperative patients, because hypotension can be avoided while controlling heart rate, and infusion of the drug can be stopped for any untoward side effects with near immediate cessation of the effects

The promising results of this small investigation (only 30 patients in each arm) merits further inquiry, but caution should be exercised in the interpretation of the reported outcomes. Often small trials show excellent results in the initial groups but larger studies do not support the initial enthusiasm. Outcomes after a large, randomized study may or may not support the use of landiolol because it may not 
be as efficacious as the small trial suggested. Or it simply may not be safe. Demonstration of safety will be a key part of the addition of any medication to the treatment regiment of a population of patients-possibly with poor left ventricular function - who historically have been sensitive to the effect of beta blockers after heart surgery. In addition, these promising results may or may not be applicable to the more general population of patients undergoing coronary bypass or other cardiac surgical procedures who do not have poor left ventricular function. If large-scale studies show that this drug is useful in populations with left ventricular failure then the natural next step will be to evaluate the drug in patients with normal hearts. If landiolol turns out to be efficacious in these groups, then investigation into patients who undergo thoracic surgery of any type would be warranted. Such trials will certainly take time to complete, so the cardiothoracic surgery community in the meantime will have to continue to treat postoperative atrial fibrillation with the limited tools available until clear evidence in large trials support the safety and efficacy of this ultrashort-acting beta blocker.

\section{References}

1. Sezai A, Osaka S, Yaoita H, Ishii Y, Arimoto M, Hata H, Shiono M. Safety and efficacy of landiolol hydrochloride for prevention of atrial fibrillation after cardiac surgery in patients with left ventricular dysfunction: prevention of Atrial Fibrillation After Cardiac Surgery With Landiolol Hydrochloride for Left Ventricular Dysfunction (PLATON) trial. J Thorac Cardiovasc Surg. 2015;150:957-64.

2. Hillis LD, Amith PK, Chair V, Anderson JL, Bittl JA, Bridges CR, et al. 2011 ACCF/AHA/guideline for coronary artery bypass grafting. A report of the American College of Cardiology Foundation/American Heart Association Task Force on Practice Guidelines. Circulation. 2011;124:e652-735.

3. Brinkman W, Herbert MA, O'Brien S, Filardo G, Prince S, Dewey T, et al. Preoperative $\beta$-blocker use in coronary artery bypass grafting surgery. National database analysis. JAMA Intern Med. 2014;174:1320-7.

4. Shen J, Lall S, Zheng V, Buckley P, Damiano RJ Jr, Schuessler RB. The persistent problem of new-onset postoperative atrial fibrillation: a single-institution experience over two decades. J Thorac Cardiovasc Surg. 2011;141:559-70. 